\title{
Pyrolysis Gas as a Renewable Reducing Agent for the Recycling of Zinc- and Lead-Bearing Residues: A Status Report
}

\author{
C. PICHLER (iD ${ }^{1,2}$ and J. ANTREKOWITSCH ${ }^{1}$ \\ 1.-Department of Nonferrous Metallurgy, Montanuniversitaet Leoben, Franz-Josef-Straße 18, \\ 8700 Leoben, Austria. 2.—e-mail: christoph.pichler@unileoben.ac.at
}

\begin{abstract}
The topic "Zero Waste" has been in existence for several years in the industry, and the metallurgical industry has also made efforts to reduce the amounts of residues occurring and have started several investigations to cut down on metallurgical by-products which have to be landfilled. Especially, the additional costs for $\mathrm{CO}_{2}$ emissions in different metallurgical steps have led to investigations into alternative carbon carriers. Charcoal has been identified to serve as an ideal substitute due its $\mathrm{CO}_{2}$-neutrality. For the applications of this renewable carbon carrier in metallurgical processes, charcoal production by means of a carbonization process needs to be optimized. As a by-product during the heating of agricultural wastes or wood by excluding air, pyrolysis gas occurs. Due to the existence of combustible compounds in this gas, an application as a reduction agent instead of fossil carbon carriers in metallurgy is possible. Based on the prevention of dumping metallurgical by-products, an investigation has been developed to treat zinc- and lead-containing materials. To realize this, a dedicated process concept has been designed and developed. As the main focuses, the usage of the pyrolysis gas from charcoal production for the Waelz kiln process and the recycling of zinc- and lead-containing Waelz slag, resulting from the processing of steel mill dust in a vertical retort, have to be mentioned. Within this research, the process concept was executed from laboratory-scale up to pilot-scale testing, described in this article.
\end{abstract}

\section{INTRODUCTION}

Currently, the assignment of renewable resources for different applications is a big challenge. Especially in metallurgy, there is a wide range of primary resources used to generate various metals or products. In most cases, a carbon carrier is used as an energy source or reducing agent, accompanied by the generation of carbon dioxide. Regarding the high costs for carbon dioxide certificates 5 or 6 years ago, different surveys were started in order to look for renewable reducing agents and energy resources to reduce the carbon dioxide output and lower the costs for the carbon dioxide certificates needed. One promising possibility was to use agricultural waste or wood in a carbonization process to obtain charcoal as a carbon dioxide-neutral carbon carrier. Such a process is used, but, for the usage of charcoal in a metallurgical application, some special characteristics are required. During the pyrolysis of biomass or wood, the so-called pyrolysis gas occurs as a by-product. It consists of burnable compounds, carbon dioxide and condensable tars. ${ }^{1}$ In industrial pyrolysis units, this gas is used to heat the pyrolysis unit itself, but it is also possible to use it as a reducing agent for metallurgical applications. The idea of renewable energy or reducing agents in metallurgy was tested in a recycling concept to treat zinc- and lead-containing process waste.

One option of using charcoal in metallurgy is provided by steel mill dust recycling. The Waelz process, which is a rotary kiln facility, is currently the state-of-the-art technology to recycle zinc as Waelz oxide from steel mill dust. In this process, it is possible that charcoal becomes mixed with other input materials from the Waelz kiln and, consequently, this carbon carrier is used for the reduction of zinc compounds to metallic zinc which evaporates and enters the off-gas stream to separate it from the slag bulk. A disadvantage of this process is the high amount of remaining Waelz slag, which still 


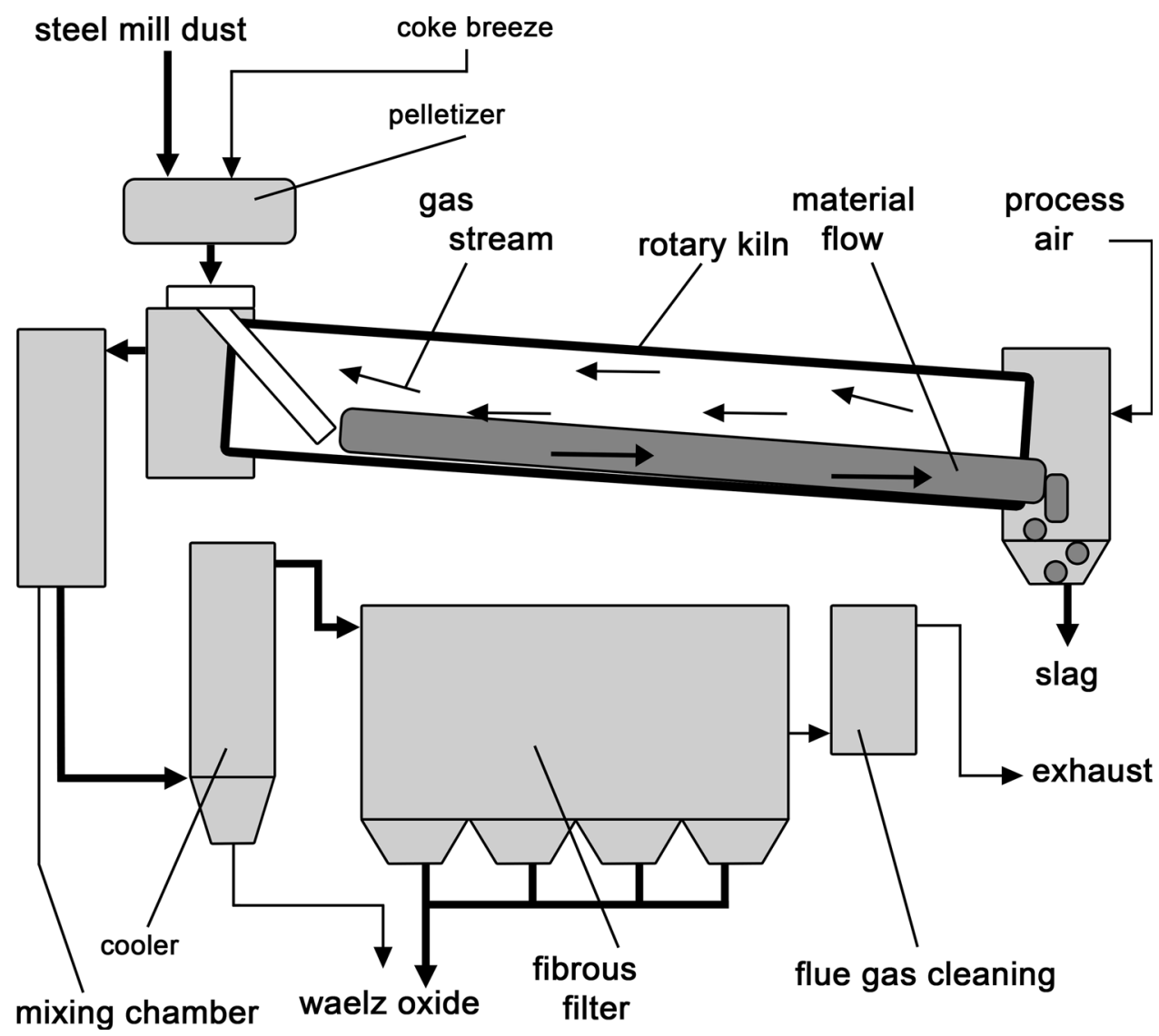

Fig. 1. Waelz process route. ${ }^{5}$

contains zinc and lead, and the elution behavior of this residual slag hinders it from being used as a secondary resource in other applications.

In order to prevent any dumping, an additional treatment of the Waelz slag generated is a target for the future. One possibility could be a so-called vertical retort, where the low evaporation point of the metallic zinc is used to concentrate the zinc in the off-gas as zinc oxide. To realize this, the material is heated up in a vertical retort with a range of $1050-1150^{\circ} \mathrm{C}$, and the pyrolysis gas of the charcoal production for the Waelz kiln flows through the solid Waelz slag bulk. For the resulting slag, two options remain, which are described later.

The present article describes some fundamental basics of the Waelz process and the process of removing zinc via the off-gas. It aligns with the published results of the above-mentioned retort concept. The parameters for such a process have already been defined in laboratory- and technical-scale trials and published, ${ }^{2}$ whereas this article describes investigations in a pilot-scale unit for treating Waelz slag.

\section{WAELZ SLAG GENERATION}

The dominating process for steel mill dust recycling nowadays is the Waelz process, where zinccontaining materials, especially flue dust from the iron and steel industry, are mixed with different additives and carbon-based reducing agents. The operating temperature is about $1100^{\circ} \mathrm{C}$. Through the reduction of zinc-containing compounds by carbon or carbon monoxide, the resulting zinc vapor becomes reoxidized by air introduced in the upper part of the kiln and is then collected in the baghouse filter; it is possible to separate the zinc from the rest of the charged material. As the main impurities in the Waelz oxide-the zinc-containing product generated-halogen compounds and some other undesirable impurities have to be mentioned. Lead compounds are also mainly accumulated in the formed dust. Figure 1 shows the scheme of the Waelz process. ${ }^{3,4}$

The main reaction to recover zinc is to reduce the oxidic zinc compounds via CO. Due to the low volatilization temperature, the generated metallic zinc evaporates at $907^{\circ} \mathrm{C}$. To accumulate the zinc and manage a separation of the bulk, a reoxidation needs to be done in the freeboard of the Waelz kiln, which is connected with a remarkable quantity of heat energy generation. This energy is used to heat the feeding material that enters the kiln in the upper part. The rest of the bulk forms the remaining slag, which leaves the furnace in the lower part of the kiln and is cooled in water. Regarding the partly available heavy metals in the so-called Waelz slag, a 


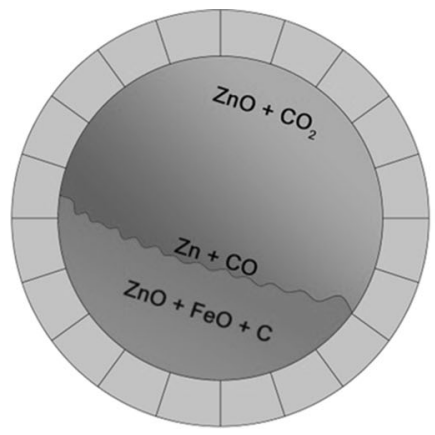

\begin{tabular}{l} 
Reaction in the gas phase (oxidizing) \\
\hline$\{\mathrm{Zn}\}+1 / 2\left\{\mathrm{O}_{2}\right\} \rightarrow \mathrm{ZnO}$ \\
$\{\mathrm{CO}\}+1 / 2\left\{\mathrm{O}_{2}\right\} \rightarrow\left\{\mathrm{CO}_{2}\right\}$ \\
\hline $\mathrm{Zn}\}+\{\mathrm{CO}\}+\left\{\mathrm{O}_{2}\right\} \rightarrow \mathrm{ZnO}+\left\{\mathrm{CO}_{2}\right\}$
\end{tabular}

Reaction in the charge (reducing)

$(\mathrm{ZnO})+\{\mathrm{CO}\} \rightarrow\{\mathrm{Zn}\}+\left\{\mathrm{CO}_{2}\right\} \quad(\mathrm{FeO})+\{\mathrm{CO}\} \rightarrow \mathrm{Fe}+\left\{\mathrm{CO}_{2}\right\}$

$\frac{\left\{\mathrm{CO}_{2}\right\}+\mathrm{C} \rightarrow 2\{\mathrm{CO}\}}{(\mathrm{ZnO})+\mathrm{C} \rightarrow\{\mathrm{Zn}\}+\{\mathrm{CO}\}} \frac{\left\{\mathrm{CO}_{2}\right\}+\mathrm{C} \rightarrow 2\{\mathrm{CO}\}}{(\mathrm{FeO})+\mathrm{C} \rightarrow \mathrm{Fe}+\{\mathrm{CO}\}}$

Fig. 2. Main reactions in the Waelz kiln.

further application is not possible since the whole amount of Waelz slag gets dumped. The main reactions occurring within the Waelz kiln can be seen in Fig. 2.,6

A wide range of different technologies for the recycling of steel mill dust have been developed or employed at industrial scale, but currently, the Waelz process has the highest market share and approximately 30-35 units are in operation worldwide, not including China. In spite of the low product quality and high amount of newly generated residues, the Waelz kiln is a simple process with a well-known principle on the one hand, and low energy consumption compared to alternatives on the other. ${ }^{7-9}$

\section{THEORETICAL PRINCIPLES AND BASICS FOR THE USAGE OF PYROLYSIS GAS IN ZINC RECOVERY}

Zinc recovery from different slags has been investigated in the past. One process realized on an industrial scale to recover zinc from liquid slag is the slag fuming process, carried out jointly with primary lead furnaces. In the process, the liquid slag is transferred into the fuming furnace and the zinc can be recovered by adding air and coal or coke through tuyères in the lower part of the reactor. At $1300-1500^{\circ} \mathrm{C}$, the added carbon reduces the zinc oxide. Such an approach separates the zinc from the liquid slag through evaporation of the metallic zinc, followed by a reoxidation in the off-gas stream. The reachable remaining zinc value is about 2 wt.\%. An overview of the reactions occurring is presented in Fig. $3 .^{10-12}$

Figure 3 shows a gas bubble with a char particle in the middle. The carbon reacts to form $\mathrm{CO}$ with the oxygen in the bubble, whereby a reducing atmosphere is generated to reduce the zinc oxide from the slag bulk. Concerning the process temperature, the vaporous zinc accumulates in the gas bubble. In this reduction, $\mathrm{CO}_{2}$ is generated which reacts with the solid carbon to $\mathrm{CO}$ by means of the Boudouard reaction. The reducing conditions can be retained and a high zinc recovery rate achieved. During these reactions, the bubble rises in the bath as the buoyancy force of the bubble is higher than

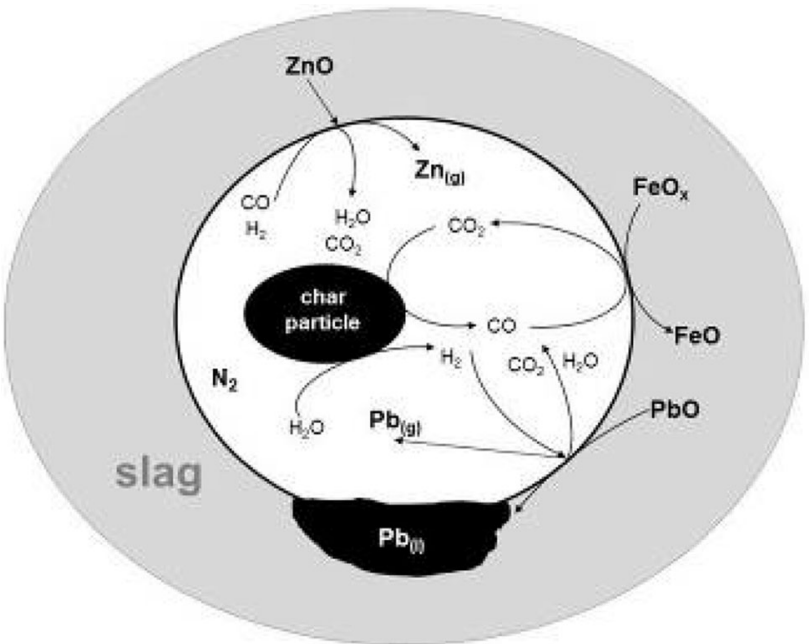

Fig. 3. Reaction system occurring in the slag fuming process. ${ }^{13}$

its weight force. When the zinc is abandoned from the slag bulk by the gas bubble, it gets reoxidized from $\mathrm{O}_{2}$ or $\mathrm{CO}_{2}$ to zinc oxide. It is therefore possible to collect the zinc oxide in the off-gas system in the baghouse filter. Typical zinc recovery yields of around $87.5 \%$ are realized. Depending on the process conditions, lead oxide is also recovered from the slag. If there is a low concentration of lead in the slag, the lead accumulates as lead oxide in the dust. If the concentration is high enough, the lead vapor accumulates in the reducing gas bubbles, condenses there and generates lead droplets which then sink to the bottom of the furnace and create a lead bath. ${ }^{12-18}$

This process deals with the extraction of zinc from a liquid slag with a solid reduction agent. In the past, the primary zinc winning process was performed in so-called "muffle" furnaces, where the zinc concentrate was mixed with a carbon carrier and heated up in a muffle, which is a closed reactor with a circular or oval cross-section. The liquid zinc removal was performed at intervals. A continuous muffle furnace was also developed to raise the throughput. These processes have since been replaced by the hydrometallurgical winning process in the primary zinc industry. ${ }^{3}$ To recover zinc from 


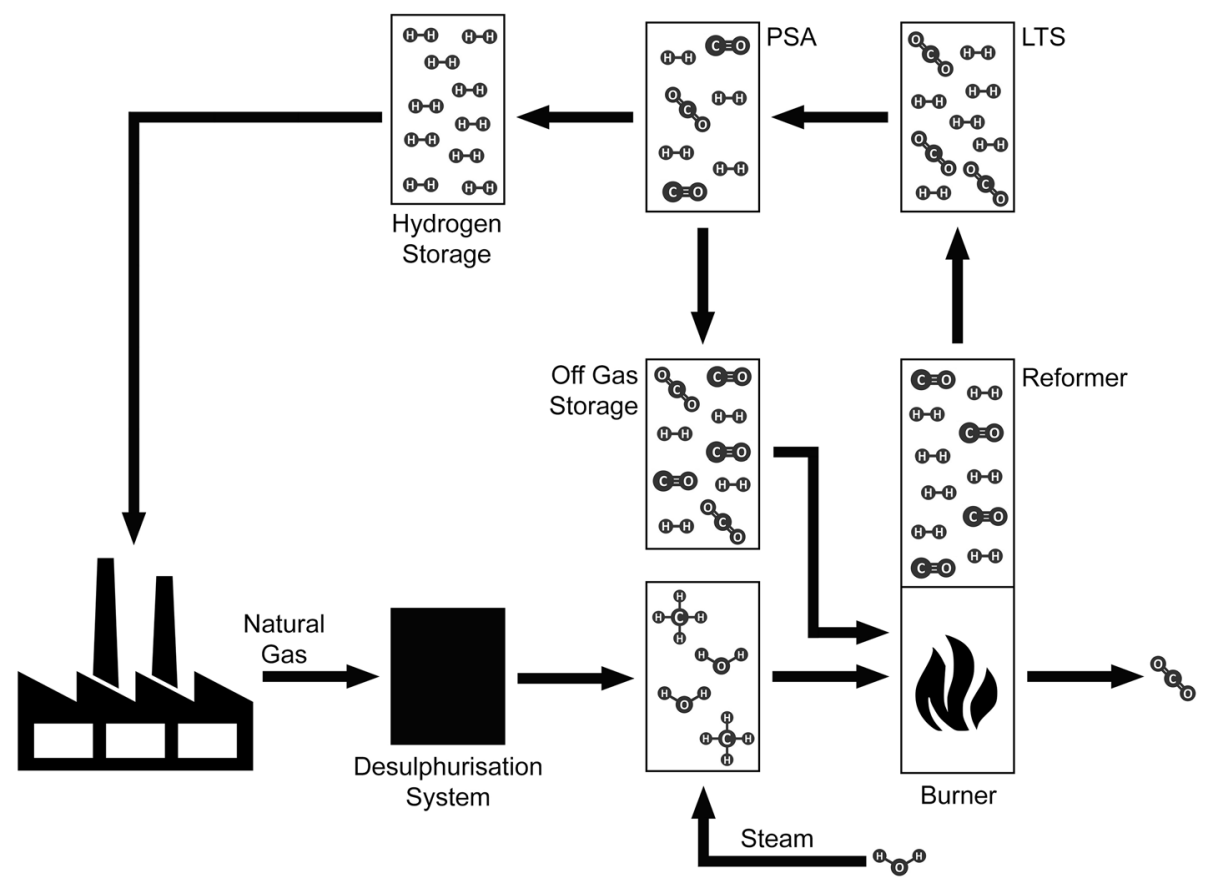

Fig. 4. Possible reforming process for pyrolysis gas to generate hydrogen.

industrial residues, the hydrometallurgical method would be very expensive and complex due to the wide range of different metals and compounds in the residues. In these times of very expensive $\mathrm{CO}_{2}$ certificates, the generation of renewable energy sources or reduction agents is important. An overall research topic has been the pyrolysis of biomass or wood to generate charcoal. Depending on the treatment conditions used, the characteristics of the generated charcoal can be affected. During the processing of biomass or wood, a mass reduction of the remaining solid charcoal takes place. As byproducts (liquid), tars and a pyrolysis gas occur. Due to the composition of the pyrolysis gas, mainly consisting of $\mathrm{CO}, \mathrm{H}_{2}, \mathrm{CO}_{2}$ and $\mathrm{CH}_{4}$, it is possible to use it as an energy resource or reductive gas for metallurgical purposes. This has led to the development of a special "vertical retort" process to treat Waelz slag, the residue from steel mill dust recycling, to recover the remaining zinc and generate an inert slag to avoid dumping. Basics for such an approach as well as initial practical results have been published. ${ }^{2}$ The next section describes the current level of development in a pilot scale testing unit.

\section{PYROLYSIS GAS FOR THE WAELZ SLAG TREATMENT}

Early investigations using pyrolysis gas to recover zinc from Waelz slag showed a possibility to perform zinc recovery through a special indirectly heated vertical retort. To achieve a better recovery yield of zinc, a reforming of the pyrolysis should be taken into account. A fundamental description of the generation of pyrolysis gas along with practical realization in technical-scale investigations are shown in the first publication of this research topic. ${ }^{2}$

The idea is to generate pure hydrogen from the pyrolysis gas through a steam reforming process, similar to how it is done with natural gas. For the existing solid-gas reaction system in the vertical retort, hydrogen is an efficient reducing agent. A possible design for a reforming process is shown in Fig. $4 .^{19}$

As a first step, desulfurization is needed to fully remove the sulfur from the system in order to prevent the used catalyst becoming inert in a following step. After this first step, the energy supply through a burner and water addition take place. Under the presence of a catalyst, the following reaction takes place ${ }^{20}$ :

$$
\mathrm{CH}_{4}+\mathrm{H}_{2} \mathrm{O} \leftrightarrow 3 \mathrm{H}_{2}+\mathrm{CO}
$$

To reduce the amount of carbon monoxide in the gas, hydrogen is generated by the water-gas shift reaction ${ }^{20}$ :

$$
\mathrm{CO}+\mathrm{H}_{2} \mathrm{O} \leftrightarrow \mathrm{H}_{2}+\mathrm{CO}_{2}
$$

Simultaneously, the splitting of long-chain hydrocarbons into carbon monoxide and hydrogen takes place and through the water-gas shift reaction, the accruing carbon monoxide reacts to hydrogen and carbon dioxide. $^{20}$

In order to separate the hydrogen from the other gases, different adsorption properties from the individual gases under higher pressure are used. The pure hydrogen generated can be used as a reducing agent. ${ }^{19}$ 


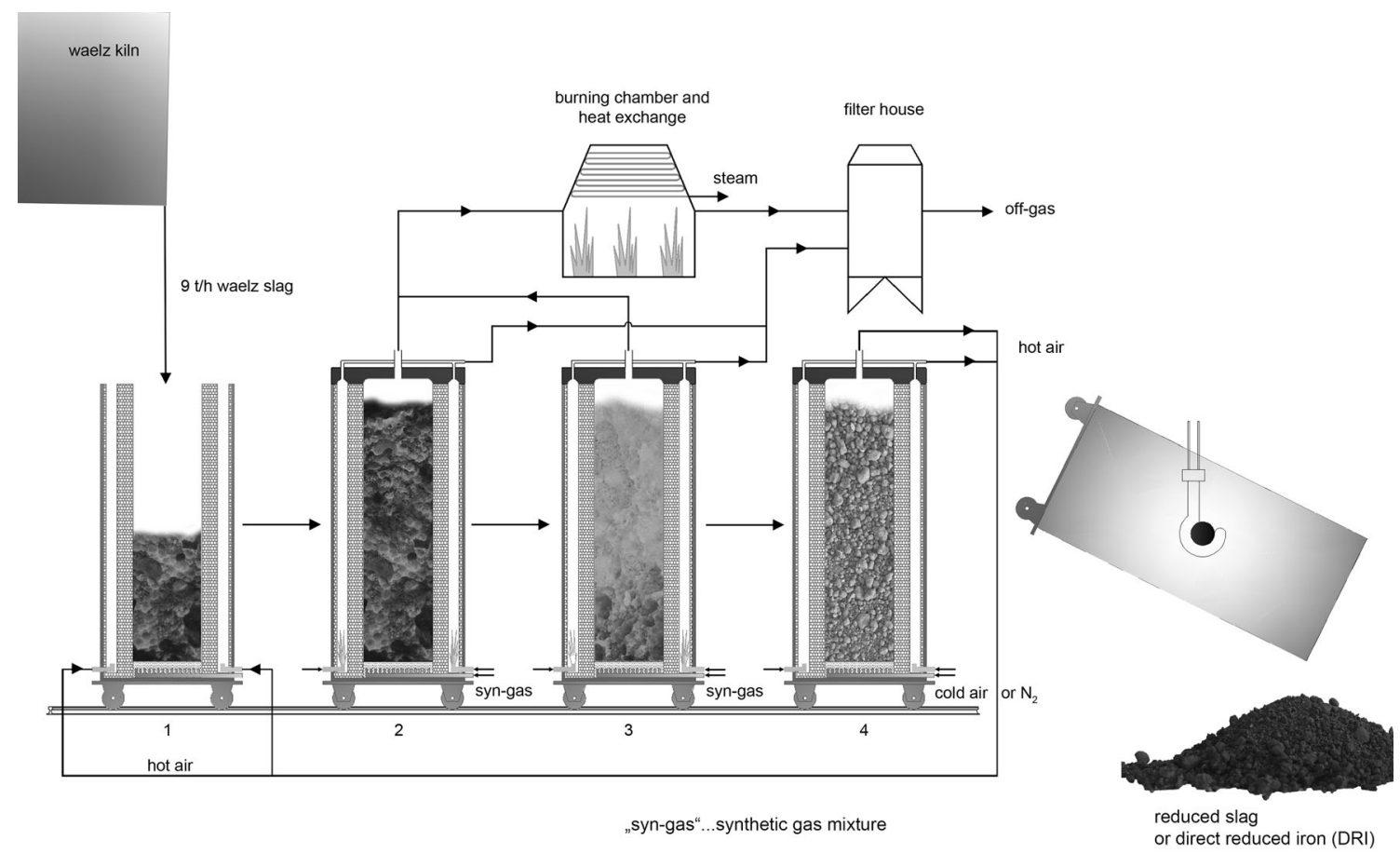

Fig. 5. Industrial realistic process flow sheet for Waelz slag treatment ${ }^{2}$ (Copyright 2015 by The Minerals, Metals \& Materials Society. Used with permission).

\section{WAELZ SLAG REDUCTION WITH PYROLYSIS GAS}

The trend towards generating renewable energy and reductive agents has led to different developments in the sector of pyrolysis from biomass. In the case of steel mill dust recycling by the Waelz process, the costs of carbon dioxide certificates and the environmental aspects are responsible for this investigation. The general idea has been to create metallurgically usable charcoal in a special reactor under previously defined conditions to use it as a carbon carrier in the Waelz kiln. As a by-product, pyrolysis gas occurs, which consists mainly of $\mathrm{CO}$, $\mathrm{CH}_{4}, \mathrm{H}_{2}$ and $\mathrm{CO}_{2}$. The values of the different gas compounds depend on the pyrolysis temperature. One possibility has been to also use this gas as a reducing agent; therefore, the investigations to treat Waelz slag in a vertical retort were started to recover the zinc from this residue and generate a slag which does not have to be landfilled.

The continuously occurring Waelz slag should be treated directly after the output from the Waelz process to lower the energy amount for heating up to the temperature needed in the retort process. A possible industrial procedure for this process combination is displayed in Fig. 5 .

Step 1 in Fig. 5 describes the hot charging of Waelz slag into the empty retort, which is indirectly heated. The idea of hot charging is to avoid a huge temperature loss. In step 2, the top of the retort is covered, to collect the occurring gas streams, and the pyrolysis gas (shown as "syn-gas" in Fig. 5) gets combusted for indirect heating, while to carry out the zinc oxide reduction, the pyrolysis gas also flows through the slag bulk. Step 3 illustrates the ongoing reactions in the slag bulk. Due to the compounds of lead with halogens, lead together with zinc oxide is removed during the treatment and forms the saleable product of filter dust. To perform step 4, two different possibilities are available. Heat recovery similar to the SDHL technology ${ }^{5,21}$ from the Waelz kiln is possible by putting air through the reduced slag instead of nitrogen. The metallic iron present reacts with the oxygen; this is an exothermic reaction. The generated energy is absorbed from the gas flow and can be used for heating step 1 . Finally, the slag should be free from zinc and lead in order to use the slag for further employment but not landfilling. The other option is to use nitrogen instead of air to obtain a product similar to directly reduced iron for applications in the iron and steel industry. The impurities through different slag components should be considered in this case.

\section{APPLICATION OF THE RETORT PROCESS IN PILOT SCALE}

The preliminary results from laboratory- and technical-scale trials were published in Ref. 2 and served as a basis for the next scale-up into a batch process with $250 \mathrm{~kg}$ of treated material per trial. To get an overview of the trial history, Fig. 6 summarizes the different scales of investigation. 

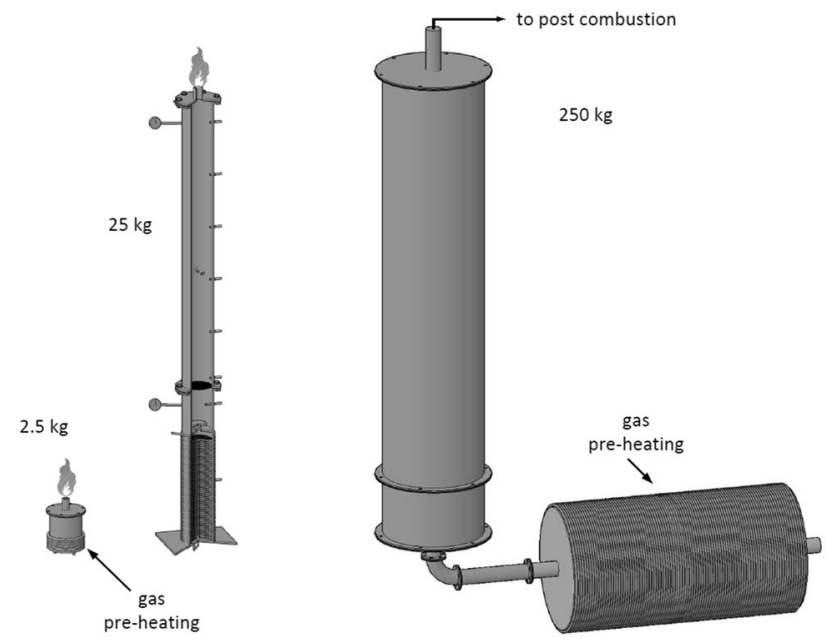

Fig. 6. Different scales of Waelz slag reduction trials.

The first trials were performed in the smallest retort with $2.5 \mathrm{~kg}$ slag per batch to define some parameters. During these investigations of the Waelz slag reduction, a development unit for the pyrolysis of biomass was also available within the research group, thus making it possible to operate these two processes simultaneously. The accumulated pyrolysis gas was collected and streamed into the Waelz slag bulk from the retort where the reduction took place by the use of gas preheating within a closed pipe system. In the next size with a capacity of $25 \mathrm{~kg}$ Waelz slag, it was impossible to combine the pyrolysis unit with the retort, because the gas amounts needed were too high and could not be provided from the pyrolysis unit in the required time. As an alternative, synthetic gas mixtures were used to perform the large number of trials. The synthetic gas compositions were adjusted to the results obtained from the biomass pyrolysis unit and pure hydrogen was also used.

After these first two stages of development, it is possible to state that the grain size distribution within the Waelz slag bulk shows no significant effect on the reachable zinc yield. It was possible to remove zinc and lead from the Waelz slag with pyrolysis gas from the charcoal production, but the usage of pure hydrogen led to better results. After a detailed interpretation of the results, the decision was made to perform trials with $250 \mathrm{~kg}$ of Waelz slag per batch and hydrogen as a reductive gas at a temperature of $1100^{\circ} \mathrm{C}$.

The pilot-scale retort ( $250 \mathrm{~kg}$ capacity) is similar to the smaller device with $25 \mathrm{~kg}$. The retort reaction room is manufactured from a heat-resistant steel. The difference is in the gas preheating unit, which is a special development for this research unit and has different heating zones to reach the target gas temperature, and is also distinguished in the type of configuration (Fig. 6). The reaction room itself is indirectly heated by resistance. At the top, postcombustion takes place whereby the metallic zinc in

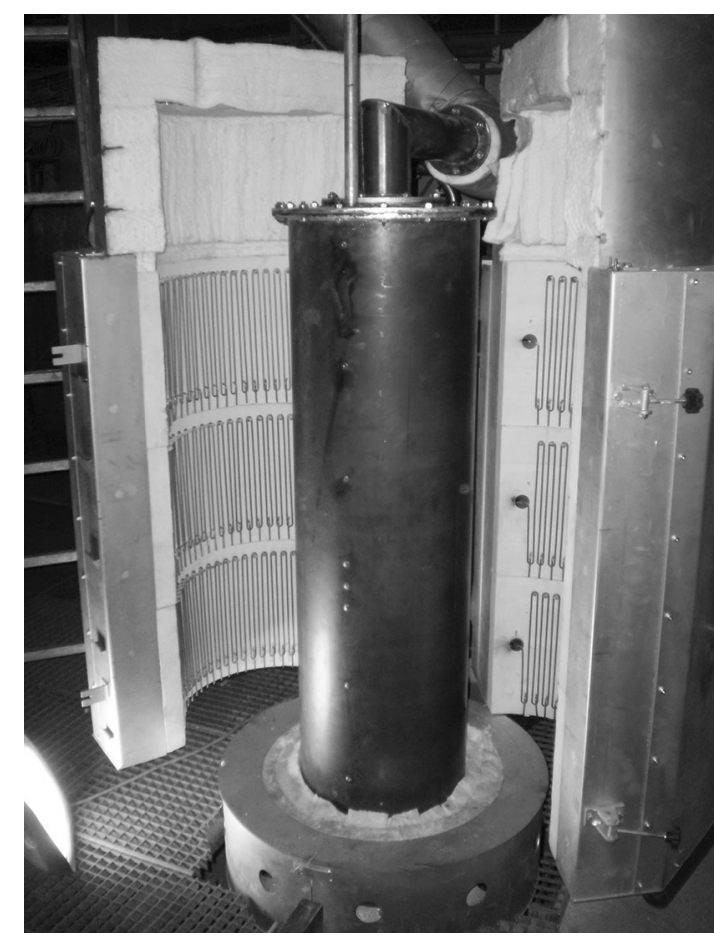

Fig. 7. Retort used for the pilot scale trials.

the off-gas gets reoxidized and any combustible compounds still present burn. The zinc oxide gets collected in a baghouse filter. The practical device can be seen in Fig. 7 .

Regarding the great effort for each test, only two defined process condition trials were performed successfully, but to evaluate the reproducibility, both trials were repeated four times under the same conditions. The process conditions for the $250 \mathrm{~kg}$ retort trials were defined according to the experience from the smaller scale trials performed. Table I gives an overview of the parameters used for the trials.

These trials were realized with the same sample material as the previous investigations. The results are summarized in Fig. 8.

The bars in Fig. 8 are the arithmetic means of different trials carried out under the same conditions. For the interpretation, the iron metallization and the zinc and lead yield were considered. It was possible to remove up to $90 \mathrm{wt} . \%$ of the zinc from the Waelz slag. The removability of lead in this type of treatment is lower but the values of lead in the slag used for the trial are also much lower compared to the zinc content. To reach such high zinc removal rates, the reduction of iron also took place. With temperatures above $1100^{\circ} \mathrm{C}$, it is possible to lower the iron reduction, but, with the available retort equipment, it was not possible to operate at higher temperatures, the reasons for this being the thermodynamic fundamentals, described in detail in Ref. 2. 
Table I. Experimental parameter design for the 250-kg Waelz slag trials

\begin{tabular}{|c|c|c|c|c|c|}
\hline Trial & $\boldsymbol{T}\left({ }^{\circ} \mathrm{C}\right)$ & Treatment time (h) & Gas & Stoichiometry & Grain size \\
\hline RG1 & 1100 & 2 & $\mathrm{H}_{2}$ & 1.5-times & OWSC \\
\hline RG2 & 1100 & 2 & $\mathrm{H}_{2}$ & 2 -times & OWSC \\
\hline
\end{tabular}

OWSC Original Waelz slag condition.

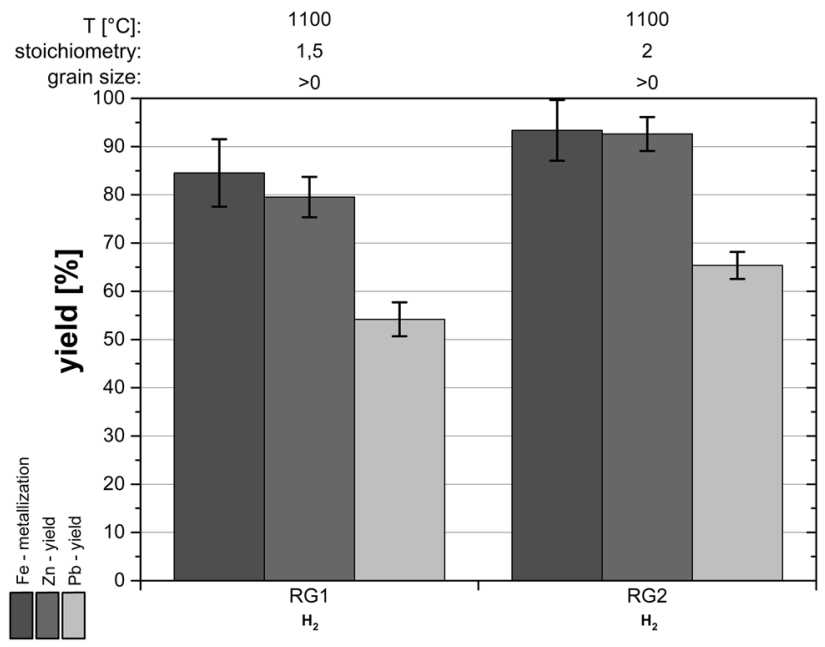

Fig. 8. Results from the pilot scale retort.

By comparing the two trials, RG1 and RG2, it can be observed that the higher amount of available reducing agent leads to much better results, but the gas utilization factor is much lower. To operate in an economical and ecological way, an off-gas cleaning and re-usage of the process is becoming necessary.

To sum up, the three main parameters of temperature, grain size and reduction gas can be evaluated. For a high zinc recovery and lower iron reduction, the temperature should be as high as possible in the facility used. The limitation is the sintering temperature because this can reduce the gas permeability and then it is impossible to proceed with the process. The defined temperature for zinc removal with an acceptable sintering behavior is about $1150^{\circ} \mathrm{C}$. The occurring slag from the Waelz process is not a typical slag as known from a process in liquid state, as it does not melt in the Waelz kiln and only agglomerates to a crumby material, which can be used directly in a retort reactor for additional reduction. To determine the influence of the different particle sizes, trials with different grain categories were performed. The difference when comparing these trials was negligible. These trials demonstrated the possibility of using pyrolysis gas directly from a pyrolysis unit to recycle zinc from Waelz slag. For better results, it is necessary to perform a reformation and use the resulting hydrogen as a reducing agent. Another advantage of such an approach is the splitting of the hydrocarbon chains that get generated during the pyrolysis of biomass or wood.

\section{CONCLUSION}

The present article describes a possible treatment of Waelz slag with pyrolysis gas which derives from the metallurgical charcoal production of biomass or wood and contains huge quantities of combustible components. In a vertical retort, the pyrolysis gas flows through an indirectly heated Waelz slag bulk and, in the process, the zinc gets reduced and separates from the rest of the slag bulk by means of evaporation. The metallic zinc in the off-gas reoxidizes outside the retort through the oxygen in the air provided and can be collected in the baghouse filter of the off-gas system. Lead or some lead compounds also follow the zinc into the gas phase. The metallic iron generated also remains in the solid material. These investigations were done at different scales, from laboratory-scale trials up to so-called pilot-scale, with $250 \mathrm{~kg}$ of treated material per batch. Different parameters were defined in the performed trials and, in the end, it was possible to evaluate such a Waelz slag recycling process from different points of view.

The treatment facility employed is currently not a state-of-the-art process or technology, and therefore only limited information about the performance of such a technology at an industrial scale is available.

The idea for this development was the usage of renewable energy or reducing agents in metallurgy and the costs of the $\mathrm{CO}_{2}$ certificates. At present, these certificates are not a crucial factor for the producers of Waelz slag, which is why many investigations on this topic have been stopped. Moreover, the research to generate charcoal by a special pyrolysis unit was stopped and therefore no pyrolysis gas occurs which can be used for such a retort concept.

To perform such a process, it is necessary to do a reforming of the pyrolysis gas, which generates additional costs for the operation. Due to the prices of available primary resources, any operation is too expensive. A complex additional gas cleaning unit to raise the gas occupancy rate is also necessary. 
The residue remaining after the reduction consists mainly of metallic iron. Due to the high amount of impurities, it is not possible to use it as directly reduced iron in the iron and steel industry and it also has to be dumped.

Concerning the reasons discussed, the research project was stopped at the pilot-scale testing phase and some optimizations will be necessary in order to be able to perform such a process on an industrial scale. In the case of Waelz slag treatment, the investigations will be continued by carrying out a complete reduction in the liquid state together with other zinc- and lead-containing residues.

\section{ACKNOWLEDGEMENTS}

Open access funding provided by Montanuniversitaet Leoben. The present work has been funded by the Austrian Federal Ministry of Science, Research and Economy, and the authors would like to thank the whole team of the Christian Doppler Laboratory for Optimization and Biomass Utilization in Heavy Metal Recycling at the Chair of Nonferrous Metallurgy at Montanuniversitaet Leoben, Austria. We would also like to thank the Regional Innovation Center on Raw Materials for East- and South-East Europe, RIC ESEE, at Montanuniversitaet Leoben for their assistance in the preparation of this article.

\section{OPEN ACCESS}

This article is distributed under the terms of the Creative Commons Attribution 4.0 International License (http://creativecommons.org/licenses/by/4.0/), which permits unrestricted use, distribution, and reproduction in any medium, provided you give appropriate credit to the original author(s) and the source, provide a link to the Creative Commons license, and indicate if changes were made.

\section{REFERENCES}

1. P. Basu, Biomass Gasification and Pyrolysis, 1st ed. (Burlington: Academic Press, 2010).
2. C. Pichler and J. Antrekowitsch, JOM 67, 2038 (2015).

3. F. Pawlek, Metallhüttenkunde, 1st ed. (Berlin: Walter de Gruyer, 1983).

4. J. Rütten, C. Frias, G. Diaz, D. Martin, and F. Sanchez, Proceedings of EMC 2011, vol. 1673 (2011).

5. E. Saage and U. Hasche, World Metall. ERZMETALL 57, 138 (2004).

6. P.A. Kozlov, The Waelz Process, 1st ed. (Moskau: Ore and Metals Publishing House, 2003).

7. J. Rütten, Seminar Networking Between Zinc and Steel, 3rd ed. (Clausthal-Zellerfeld, Germany: GDMB Society for Mining, Metallurgy, Resource and Environment Technology e. V., 2011), p. 77.

8. L.M. Southwick, Zinc Recovery from Electric Arc Furnace (EAF) Dust (Lisboa: International Lead and Zinc Study Group, 2015).

9. H. Bartusch, F. Alcalde, A. María, and M. Fröhling, Erhöhung der Energie- und Ressourceneffizienz und Reduzierung der Treibhausgasemissionen in der Eisen-, Stahl- und Zinkindustrie, 1st ed. (Karlsruhe: KIT Scientific Pubilishing, 2013).

10. K. Heale, O. Bot, K. Klimchuk, and D. Rioux, Zinc and Lead Metallurgy, ed. L. Centomo (Wiley-VCH, Weinheim, 2008), p. 53.

11. K. Heale, O. Bot, K. Klimchuk, and D. Rioux, Zinc and Lead Metallurgy, ed. A. Siegmund (Wiley-VCH, Weinheim, 2010), p. 1087.

12. G. Haralampiev and N. Popov, Can. Metall. Q. 38, 1 (1999).

13. R. Püllenberg and R. Höhn, Schriftenreihe der GDMBGesellschaft für Bergbau. Metall. Rohst. Umwelttech 83, 81 (1999).

14. W. Gao, C. Wang, F. Yin, Y. Cheng, and W. Yang, Adv. Mater. 24, 581 (2012).

15. K. Koch, Schlacken in der Metallurgie, 1st ed. (Düsseldorf: Verl. Stahleisen, 1984).

16. E. Jak and P. Hayes, Can. Metall. Q. 42, 163 (2002).

17. E. Worrell and M.A. Reuter, Handbook of Recycling, 1st ed. (Waltham: Elsevier, 2014), p. 121.

18. W. Snelgrove and J.C. Taylor, Can. Metall. Q. 20, 231 (1981).

19. B.V. HyGear, Hydrogen Generators. http://hygear.com/ technologies/hy-gen/. Accessed at 12.01.2015.

20. T.L. Levalley, A.R. Richard, and M. Fan, Int. J. Hydrogen Energy 39, 16983 (2014).

21. R. Remus, S. Roudier, M.A. Aguado-Monsonet, and L. Delgado Sancho, Best Available Techniques (BAT) Reference Document for Iron and Steel Production (Luxembourg: Publications Office, 2013). 